Copyright (C) 2013 IEEE. Personal use of this material is permitted. Permission from IEEE must be obtained for all other uses, in any current or future media, including

reprinting/republishing this material for advertising or promotional purposes, creating new collective works, for resale or redistribution to servers or lists, or reuse of any copyrighted component of this work in other works. 


\title{
Application of SMES Unit to Improve DFIG Power Dispatch and Dynamic Performance during Intermittent Misfire and Fire-through Faults
}

\author{
A. M. Shiddiq Yunus, A. Abu-Siada, Senior Member, IEEE and \\ Mohammad A.S. Masoum, Senior Member, IEEE
}

\begin{abstract}
The number of wind turbines connected to power grids has significantly increased during the last decade. This is mainly due to the convincing revolution in power electronic technology and the growing concern about greenhouse effect that is intensified due to the burning of fossil fuels. Variable speed wind energy conversion systems (WECS) such as doubly fed induction generators (DFIG) are dominating the wind energy market due to their superior advantages over fixed speed-based WECS that include more captured energy, less mechanical stress and acoustical noise. DFIG is interfaced to the ac network through grid side voltage source converter (GSC) and rotor side voltage source converter (RSC) to enable the variable speed operation of the wind turbine and to provide reactive power support to the ac grid during disturbance events. Converter switching malfunction such as misfire and fire-through may influence the power dispatch capability of the DFIG. In this paper, a super conducting magnetic energy storage (SMES) unit is utilized to improve the power dispatch and dynamic performance of DFIG-based WECS during internal converter switching malfunctions such as misfire and fire-through faults. Simulation results without and with SMES connected to the system are presented, compared and analyzed.
\end{abstract}

Index Terms-DFIG, Fire-through, Misfire, and SMES.

\section{INTRODUCTION}

$\mathbf{T}$ HE urgent need for considering a large portion of renewable energy as main power supply has become a trigger for wind energy technology development since the assignment of Kyoto Protocol in 1997 [1]. Wind energy market was initiated with fixed speed wind energy conversion systems (WECS) in 1990s [2]. However, since fixed speed WECS are limited in tracking optimal wind energy, have poor performance in wind gust conditions and offer low contribution during various grid faults [2, 3], variable speed WECS technology such as AWT-26 DFIG was introduced to the modern wind energy market in 1998 [4]. In variable speed WECS; the generator is interfaced to the ac network through voltage source converters which are controlled to enable maximum energy tracking. Moreover, with proper control design it could contribute in restoring system stability during various grid faults. With the revolution in power electronic technology, variable speed WECS is currently dominating the

global WECS installation $[2,5]$. Variable speed WECS are categorized into two main types; doubly fed induction generator (DFIG) and full scale converter wind turbine. The

A. M. Shiddiq Yunus is with the Department of Mechanical Engineering, Energy Conversion Study Program, State Polytechnic of Ujung Pandang, Indonesia. A. Abu-Siada and M.A.S. Masoum are with the Department of Electrical and Computer Engineering, Curtin University, Perth,WA, Australia (shiddiq@poliupg.ac.id,a.abusiada@curtin.edu.au, m.masoum@curtin.edu.au) one-third rated size of DFIG's converters makes it more attractive than the latter. In 2004, DFIG has reached 55\% of the total installed WECS worldwide [5]. The voltage source converters that interface the DFIG and the ac grid are considered as the crux of the system. The rotor side converter (RSC) controls the DFIG generated power while grid side converter (GSC) controls the voltage level across the dc-link capacitor.

While there are some studies about the effect of internal converter station faults such as misfire and fire-through on the performance of high voltage direct current (HVDC) systems [6], no attention has been given to investigate the impact of such faults on the overall performance of the DFIG-based WECS and to its compliance with the recent developed grid codes during such faults. Misfire is the failure of the converter switch to take over conduction at the programmed conducting period while fire-through is the failure of the converter switch to block during a scheduled non-conducting period. These internal faults are caused by various malfunctions in the control and firing equipment [7]. An industrial survey shows that converter faults due to malfunctions within the control circuit represent about $53.1 \%$ while about $37.9 \%$ of the converter faults are due to converter power parts [8],[9]. Some of converter faults are self clearing if the causes are of transient nature, however they can still have a detrimental impact on the system particularly when they occur within inverter station rather than rectifier station [10]. The use of insulated gate bipolar transistor (IGBT) in both DFIG's converters is preferred due to its advantage which include high switching frequency in a typical range of $2-20 \mathrm{kHz}$ compared with the counterpart gate turn-off (GTO) transistor switching frequency which does not exceed $1.0 \mathrm{kHz}$ [2]. When a malfunction occurs on IGBT based converter station, it can cause catastrophic breakdown to the device, if the fault remains undetected [11].

In this paper, misfire and fire-through faults are simulated on the RSC and GSC of DFIG-based WECS to investigate their impacts on the dynamic performance and power dispatch of the DFIG. A new controller for superconducting magnetic energy storage (SMES) unit is then adopted to improve the dynamic performance and the power dispatch capability of DFIG during the occurrence of the aforementioned faults. Selection of SMES is based on its superior advantage over other flexible alternating current transmission systems (FACTS) devices that include rapid response, high efficiency and decoupled active and reactive power control in four-quadrant operation [12]. Faults within the RSC and GSC may lead to excess current in the converter switches and rotor windings [13]. A chopper is 
usually connected across the dc link to limit the capacitor overvoltage and to protect the converter switches during faults while a crowbar circuit is activated to protect the DFIG rotor winding against excess current during disturbance events [14].

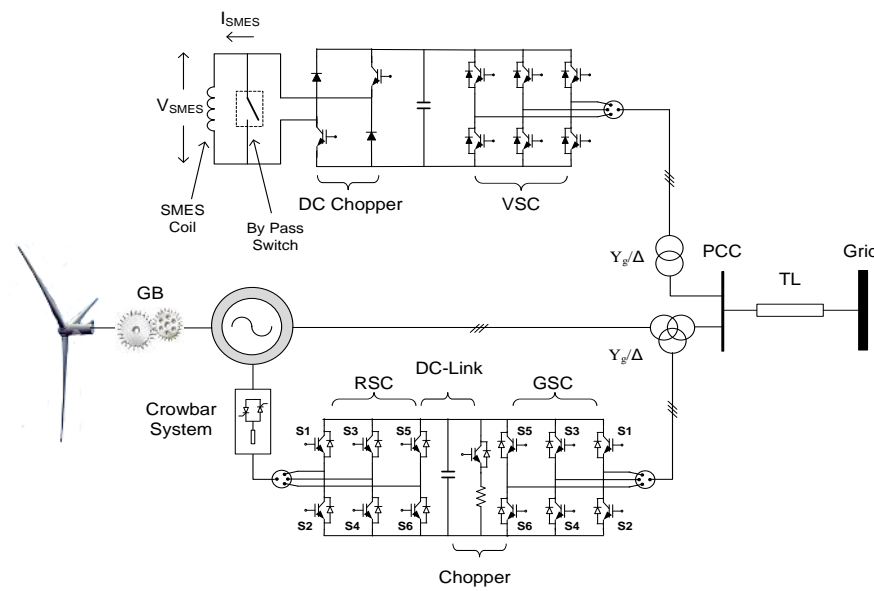

Fig. 1. System under study including DFIG equipped with SMES unit.

\section{SYSTEM UNDER STUDY}

The system under study shown in Fig. 1 consists of a single $3 \mathrm{MW}$ DFIG with its stator connected to the ac grid which is represented by an ideal three-phase voltage source of constant frequency at a point of common coupling (PCC) via coupling transformer and short transmission line (TL). The rotor windings are fed through back-to-back IGBTbased voltage source converters with a common dC-link capacitor and chopper to limit the capacitor over voltage. The DFIG grid side converter (GSC) and rotor side converter (RSC) are controlled by a four quadrant vector control as detailed in $[15,16]$. For an average wind speed of $15 \mathrm{~m} / \mathrm{s}$ used in this study, the turbine output power is regulated at $1.0 \mathrm{pu}$ which is corresponding to a rotor shaft speed of $1.2 \mathrm{pu}$. The SMES unit is connected to the PCC through a three-phase step up $\mathrm{Y} / \Delta$ transformer and is assumed to be fully charged at its maximum capacity of 1.0 MJ. Applications of SMES unit to smooth the WECS output power due to wind speed variation have been discussed in many papers in the literature such as [17]-[23]. The variability of wind speed naturally takes time in the range of several seconds to minutes while misfire and fire-through faults last for a few milliseconds. In this paper a new application for the SMES unit to overcome the impact of the later issues is introduced and hence the wind speed is assumed to be constant during the studied interval $(1.0 \mathrm{~s})$.

\section{SMES UNIT AND CONTROL SYSTEM}

A typical SMES unit (Fig. 2) consists of a superconducting coil, a power conditioning system, a cryogenic refrigerator, and a cryostat/vacuum vessel to keep the coil at a low temperature that is required to maintain SMES coil in the superconducting state. This configuration makes SMES highly efficient in storing electricity with a typical efficiency in the range of 95-98\% [24]-[26]. In addition to its high efficiency, SMES unit has the advantages of rapid transient response and smoothly decoupled active and reactive modulation in four quadrant operation that makes it suitable for high power applications [27].

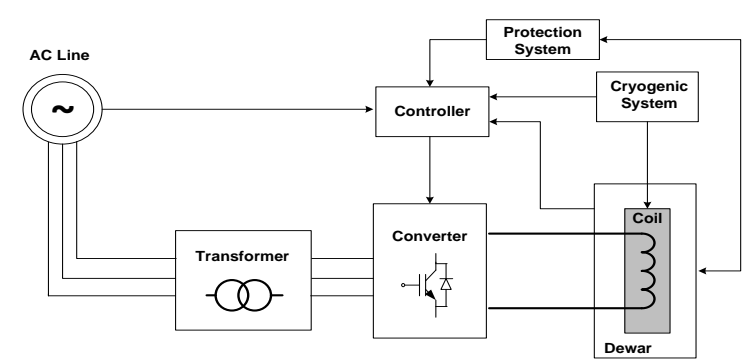

Fig. 2. Schematic diagram of a SMES unit.

The main drawback of the SMES unit is its high Grid imp implementation cost and environmental issues associated with the formation of strong magnetic field [28]. However, with the recent development of high temperature superconducting materials and the underground installation of the whole unit, applications of SMES in power systems are expected to become more popular and practical in the near future [29]. Generally, there are two major configuration of SMES; current source converter (CSC) and voltage source converter (VSC). Traditionally, CSC comprises 12-pulse converter configuration to eliminate the ac side fifth and seventh harmonic currents and the dc side sixth harmonic voltage, thus resulting in a significant saving in harmonic filters [30]. However, because this configuration uses two 6-pulse converters, its cost is relatively high. VSC on the other hand, must be connected with a dc-dc chopper through a dc-link which facilitates energy exchange between the SMES coil and the ac grid. The head to head comparison of VSC and CSC configuration is discussed in [31]. Both configurations allow decoupled control of real and reactive power. However, VSC is able to provide continuous rated VAR support even with very low coil current [31]. While the SMES unit application to stabilize WECS system during grid faults and wind variability is discussed in many papers in the literatures such as [17]-[23], [32], no attention has been given to its applications in improving system dynamics during internal VSC faults which is presented in this paper. To facilitate this new application of SMES unit, a new control algorithm based on hysteresis current control (HCC) and fuzzy logic approaches is adopted. The HCC approach is used because of its simplicity, insensitivity to load variation, fast dynamic response and inherent maximum current limiting characteristic [33]. The basic implementation of $\mathrm{HCC}$ is based on deriving the converter switching signals from the comparison of the actual phase current with a fixed tolerance band around the reference current associated with that phase. However, this type of band control is not only depending on the corresponding phase voltage but is also affected by the voltage of the other two phases [34]. The effect of interference between phases (referred as inter-phases dependency) can lead to high switching frequencies. To maintain the advantages of the hysteresis method, this phase dependency can be minimized by using phase-locked loop (PLL) technique to maintain the converter switching at a fixed predetermined frequency level 
[35]. The proposed SMES with an auxiliary PLL controller is shown in Fig. 3. HCC is comparing the three-phase line currents $\left(I_{a b c}\right)$ with the reference currents $\left(I_{a b c} *\right)$ which is dictated by $I_{d}{ }^{*}$ and $I_{q}{ }^{*}$. The values of $I_{d}{ }^{*}$ and $I_{q}{ }^{*}$ are generated through a conventional PI controllers based on the error value of $V_{d c}$ and $V_{s}$. The value of $I_{d} *$ and $I_{q} *$ are converted through Park's transformation $(d q 0-a b c)$ to produce the reference current $\left(I_{a b c} *\right.$. To control power transfer between SMES coil and the DFIG system a dc-dc chopper is used and a fuzzy logic model is developed to control its duty cycle $(D)$ as shown in Fig. 4.

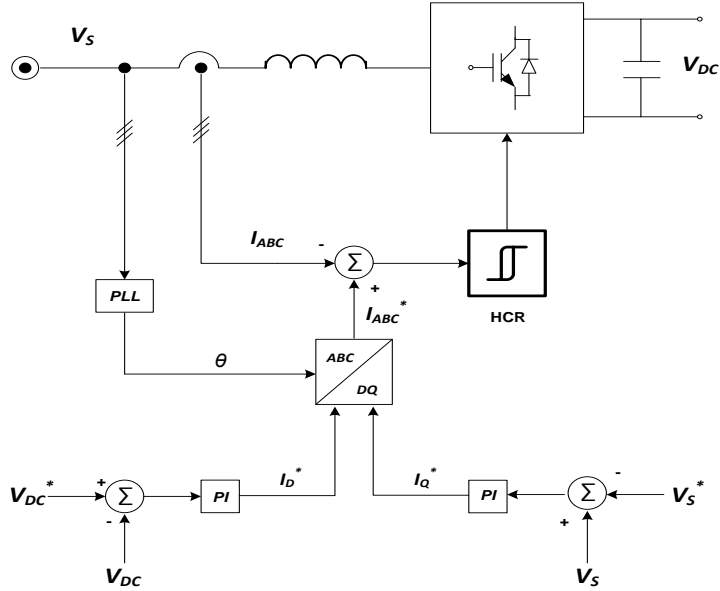

Fig. 3. Control algorithm of SMES VSC.

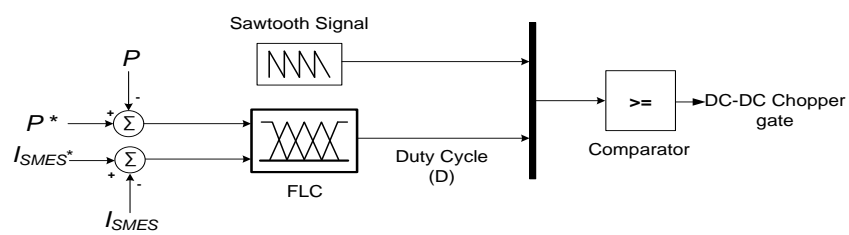

Fig. 4. Control algorithm of SMES dc-dc chopper.

Real power generated by the DFIG and the SMES coil current are considered as input variables to the fuzzy logic model. The duty cycle determines the direction and magnitude of power exchange between the SMES coil and the ac system as presented in Table I.

TABLE I

RULES OF DUTY CYCLE

\begin{tabular}{ll}
\hline \hline Duty Cycle (D) & SMES Coil Action \\
\hline $\mathrm{D}=0.5$ & standby condition \\
$0 \leq \mathrm{D}<0.5$ & discharging condition \\
$0.5<\mathrm{D} \leq 1$ & charging condition \\
\hline \hline
\end{tabular}

Under normal operating conditions, $D$ is equal to 0.5 and there is no power exchange between the SMES coil and the system. In this condition, a bypass switch that is installed across the SMES coil as shown in Fig. 1 isolates the coil to avoid the draining process of SMES energy during normal operating conditions. The bypass switch is controlled in such a way that it will be closed if $D$ is equal to 0.5 ; otherwise it will be opened to allow power exchange between the coil and the system. This technique has been introduced in some studies in the literature $[21,36]$. When the grid power is reduced, $D$ will be reduced according to the developed fuzzy logic rules to be in the range of 0 to 0.5 and the stored energy in the SMES coil will be transferred to the ac system. Charging process of the SMES coil takes place when $D$ is in the range of 0.5 to 1 . The relation between the average voltage across the SMES coil $V_{S M E S}$ and the average voltage across the dc-link capacitor of the SMES configuration $V_{D C, S M E S}$ can be expressed as [36]:

$$
V_{S M E S}=(1-2 D) V_{D C, S M E S}
$$

The model is built using the graphical user interface tool provided by MATLAB. Each input is fuzzified into five sets of gaussmf type membership function (MF). The Gaussian curve is a function of a vector, $x$, and depends on parameters $\sigma$ and $c$ as given by:

$$
f(x ; \sigma, c)=e^{-(x-c)^{2} / 2 \sigma^{2}}
$$

where $\sigma$ and $c$ are variables that determine the center of the peak and the width of the bell curve, respectively.
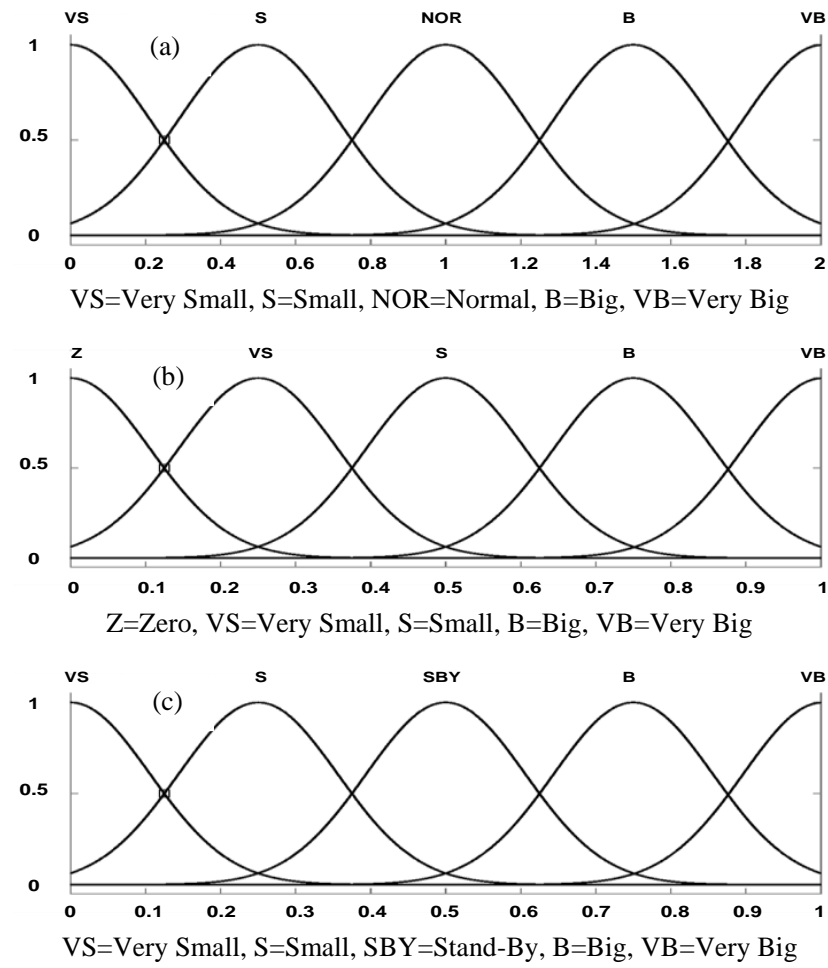

Fig. 5. Membership functions for; (a) input variable $P$, (b) input variable $I_{\text {SMES }}$, (c) output variable $D$.

The membership functions for the input variables; the generated active power $(P)$ and the current through SMES coil $\left(I_{S M E S}\right)$ are shown in Figs. 5(a) and 5(b) respectively. Membership functions for the output variable; duty cycle (D) are considered on the scale 0 to 1 as shown in Fig. 5(c).

Center-of-gravity is used for defuzzification process where the desired output $z_{0}$ is calculated as [37]:

$$
z_{0}=\frac{\int z \cdot \mu_{c}(z) d z}{\int \mu_{c}(z) d z}
$$

where $\mu_{c}(z)$ is the membership function of the output.

The variation range in SMES current and DFIG output power, along with the corresponding duty cycle are used to develop a set of fuzzy logic rules in the form of (IF-AND- 
THEN) statements to relate the input variables to the output. The duty cycle for any set of input variables ( $P$ and $\left.I_{S M E S}\right)$ can be evaluated using the surface graph shown in Fig. 6 .

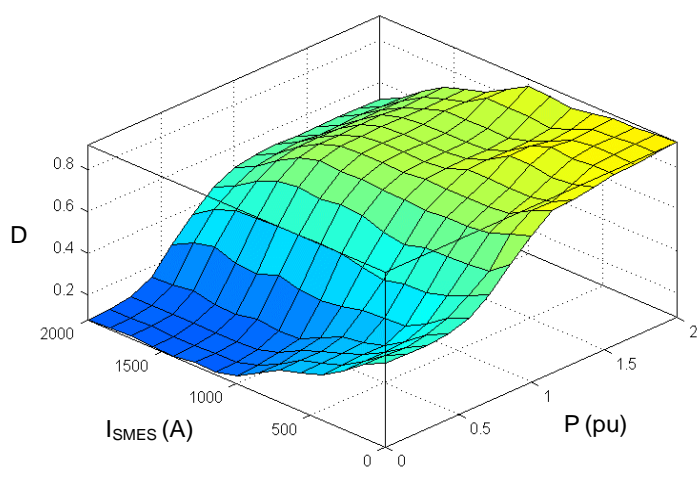

Fig. 6. Surface graph- duty cycle.

The first SMES unit rated $30 \mathrm{MJ}$ with a rated coil current of $5 \mathrm{kA}$ was installed in Bonneville power administration, Tacoma in 1982 [38]. The SMES unit capacity depends on the application and charging/discharging duration. Very high energy rating has excellent performance on damping undesired system oscillations. On the other side, if the energy rating is too low, the power modulation of the SMES unit will be limited during disturbance events and it will not be very effective in controlling system oscillations. There is no general rule for SMES unit sizing as it depends on its application and system rating. A SMES capacity of about $15 \%$ of the generator rated power was found to be sufficient to stabilise a few cycles of power interruption for the systems studied in [6] and [30]. According to [39], the optimum SMES power capacity is calculated based on its effectiveness to supply efficient damping power during the first swing of power oscillation that mainly depends on the released kinetic energy from the rotating masses of the generator during disturbance events. The SMES energy capacity is then calculated based on the designed maximum fault clearance time. The SMES calculated power capacity based on the system studied in [39] was found to be $22 \%$ of the generator rated power and the SMES energy capacity is calculated based on a maximum fault clearing time of $0.5 \mathrm{~s}$. In this paper, the power capacity of the proposed SMES unit is assumed to be $1 \mathrm{MW}$ which is corresponding to an energy capacity of $1 \mathrm{MJ}$ based on a maximum fault clearance time of 1s. As the SMES coil inductance is chosen to be $0.5 \mathrm{H}$, the inductor nominal current is $2 \mathrm{kA}$. To allow bi-directional energy exchange between the SMES unit and the ac system, the fuzzy rules are developed to allow the SMES coil to absorb up to $0.03 \mathrm{MJ}$ above its nominal steady state capacity in case of surplus energy within the ac system [40].

\section{Simulation Results}

Intermittent misfire and fire-through are simulated within the GSC and RSC of the DFIG-based WECS shown in Fig. 1. In all studied cases, the fault is assumed to occur on switch $\mathrm{S} 1$ at $\mathrm{t}=0.5 \mathrm{~s}$ and cleared at $\mathrm{t}=0.55 \mathrm{~s}$. The model parameters are given in Table II in the Appendix.

\section{A. Misfire Fault}

When a misfire is applied to the GSC, the DFIG generated power $(P)$, shaft speed and the voltage at the PCC $\left(V_{P C C}\right)$ are not significantly impacted, this is attributed to the fact that GSC has no direct connection with the DFIG and hence its influence on the dynamic performance of DFIG is trivial. This is evidenced by the slight oscillations introduced to these parameters during fault period as shown in Fig. 7.
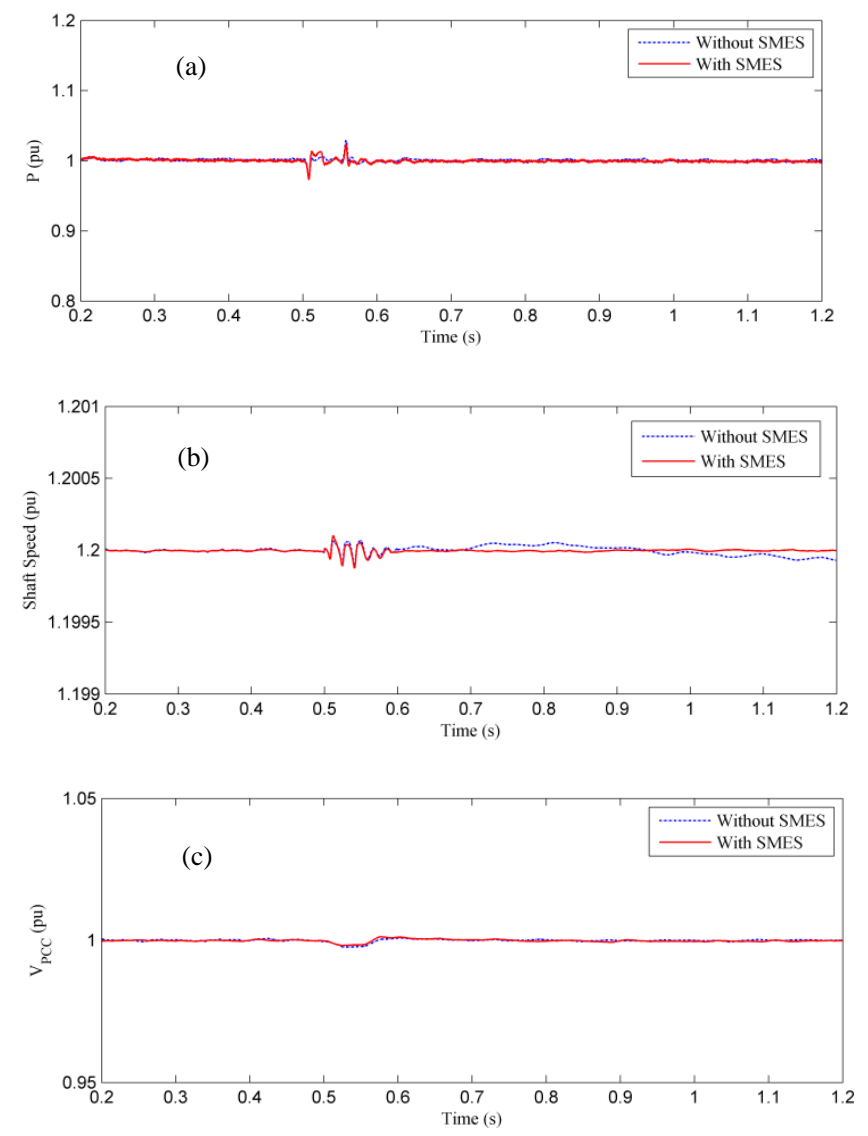

Fig. 7. Effect of GSC misfire on DFIG dynamic performance without and with SMES unit; (a) power, (b) shaft speed, (c) voltage at PCC.

When the SMES unit is connected to the system, it slightly reduces the oscillations and the settling time of the aforementioned parameters however, its contribution is not significant as all variables are within their safe standard margins. When misfire takes place within the RSC, the DFIG generated power is reduced dramatically by $60 \%$ (Fig. $8(a)$ ), shaft speed exhibits maximum overshooting at the instant of fault occurance and it does not settle down to its nominal steady state level of $1.2 \mathrm{pu}$ after fault clearance (Fig. 8(b)), and the voltage at the PCC is reduced by $6 \%$ (Fig. 8(c)). SMES unit can modulate both active and reactive power to support the system during fault events. Thus by connecting SMES unit to the system, the generated power reduction will be only $20 \%$ as shown in Fig. 8(a). The overshooting in shaft speed is reduced and the settling time is substaintially decreased as shown in Fig. 8(b). Moreover, the voltage at the PCC is also significantly improved during and after the clearance of the fault as shown in Fig. 8(c). 

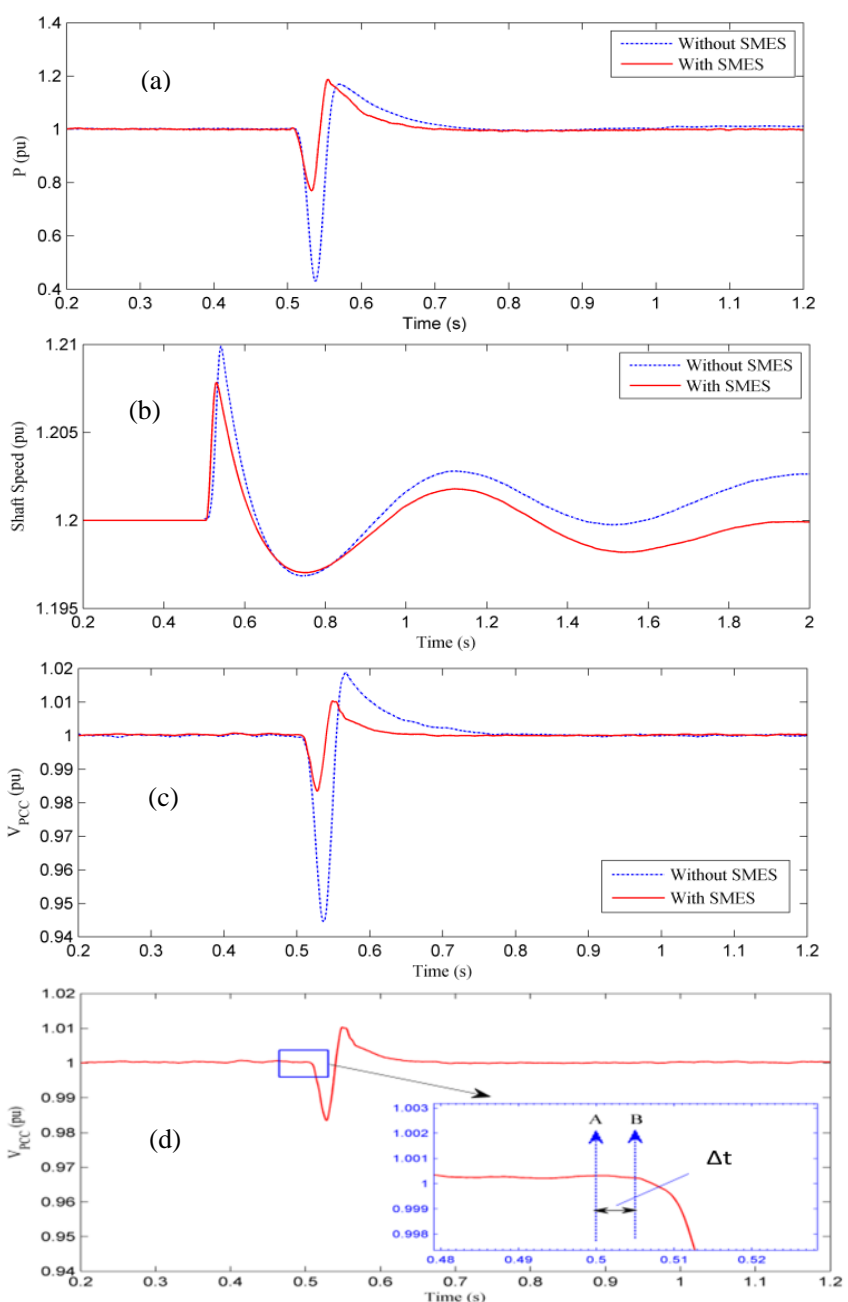

Fig. 8. Effect of RSC misfire on DFIG dynamic performance without and with SMES unit; (a) power, (b) shaft speed, (c) voltage at PCC, (d) Zoomed area of controller response time.

Fig. 8(d) shows the delay time response of the SMES controller, where point $\mathrm{A}$ is the time of fault application and point $\mathrm{B}$ is the time that the controller is functioning. As shown in the figure, this time is about $4 \mathrm{~ms}$ which proves the rapid response of the proposed controller.

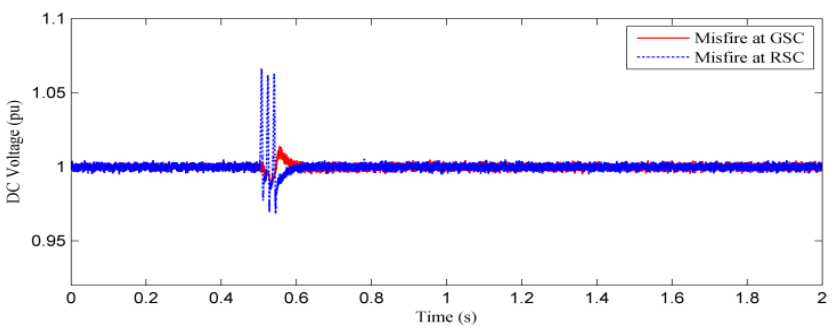

Fig. 9. Effect of GSC and RSC misfire on the DFIG dC-link voltage.

Fig. 9 Shows the voltage across the dc-link capacitor during misfire fault when occurs within GSC or RSC of the studied WECS. As shown in the figure, the voltage across the capacitor experiences a slight overshooting particularly when the misfire takes place within the RSC. However, the maximum overshooting level is still remaining within the safety acceptable margin of 1.25 pu that will not cause damages to the capacitor of the dc-link [13].
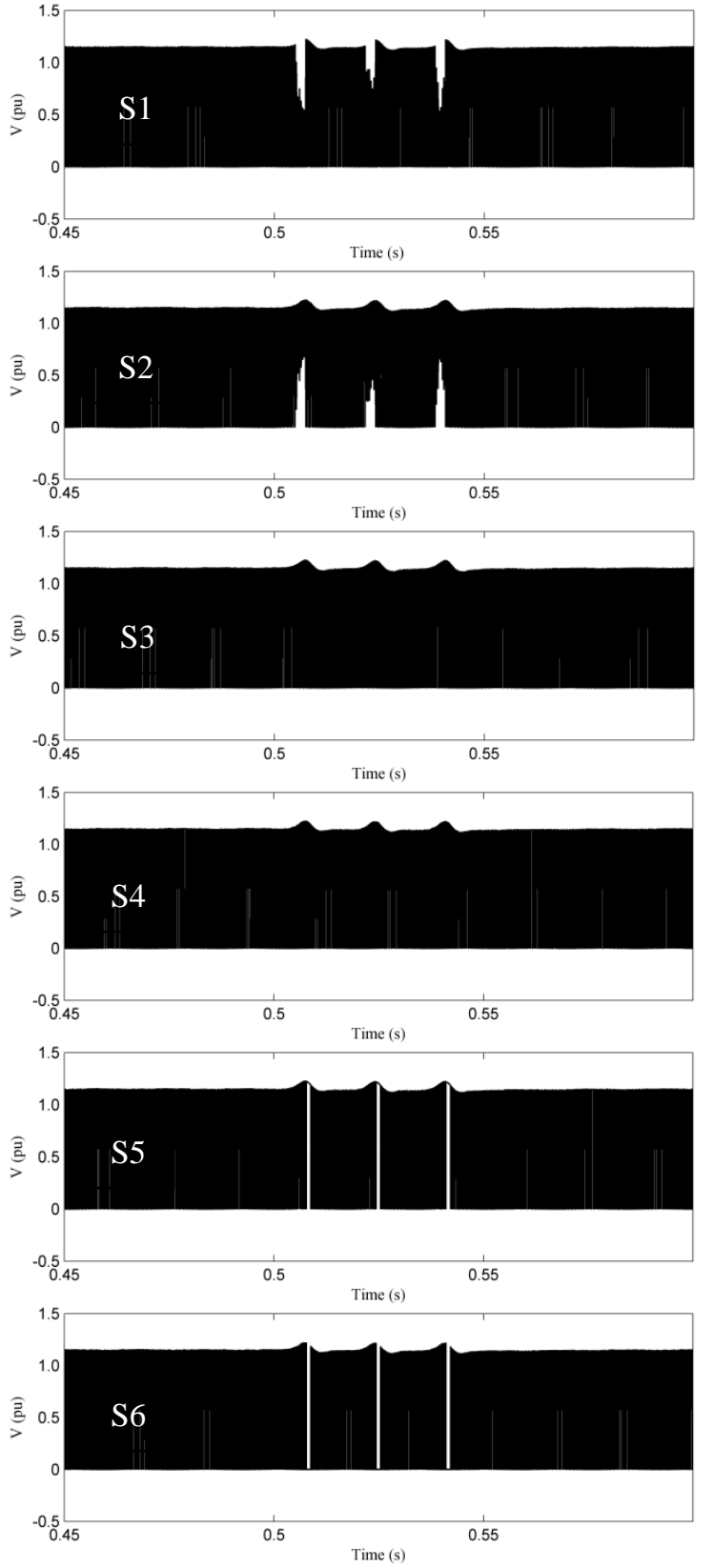

Fig. 10. Voltage across GSC switches during misfire in S1 within GSC
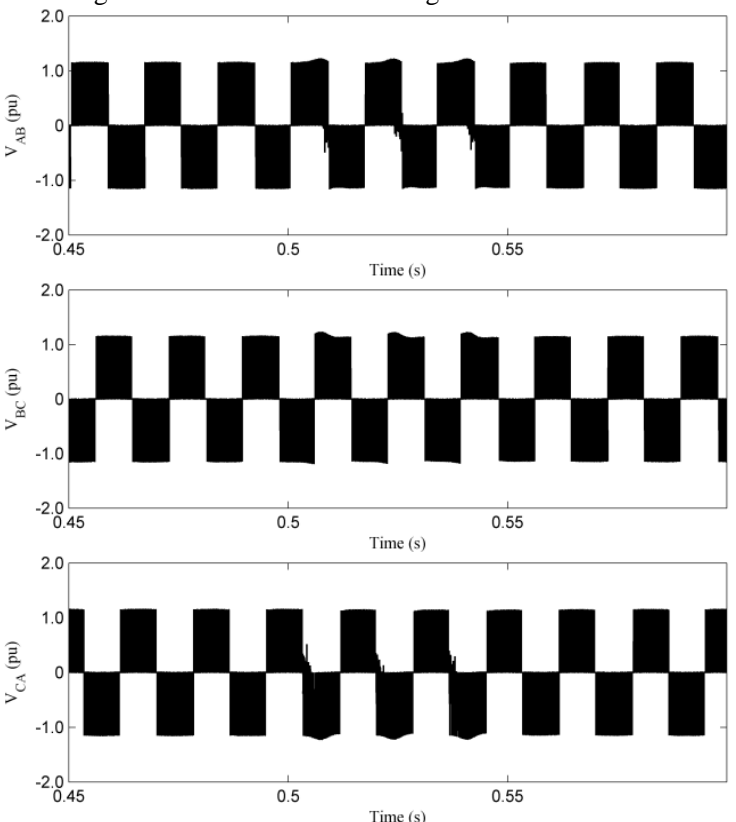

Fig. 11. Voltage across GSC terminals during misfire in S1 within GSC 
When misfire takes place on switch S1 of the GSC, the voltage pattern across GSC switches slightly changes during the fault and noticeable spikes are introduced to the terminal line voltages attached to $\mathrm{S} 1\left(\mathrm{~V}_{\mathrm{AB}}\right.$ and $\left.\mathrm{V}_{\mathrm{CA}}\right)$ as can be seen in Fig. 10 and Fig. 11, respectively. On the other hand, when switch S1 of the RSC experiences misfire, its impact on the switches voltage pattern is negligible however, it introduces significant harmonics to the RSC terminal voltages $\left(\mathrm{V}_{\mathrm{AB}}\right.$ and $\left.\mathrm{V}_{\mathrm{CA}}\right)$ as shown in Fig. 12 and Fig. 13, respectively. When misfire takes place in any other switch within the same converter, it will have the same impact on the terminal voltages attached to the faulty switch.
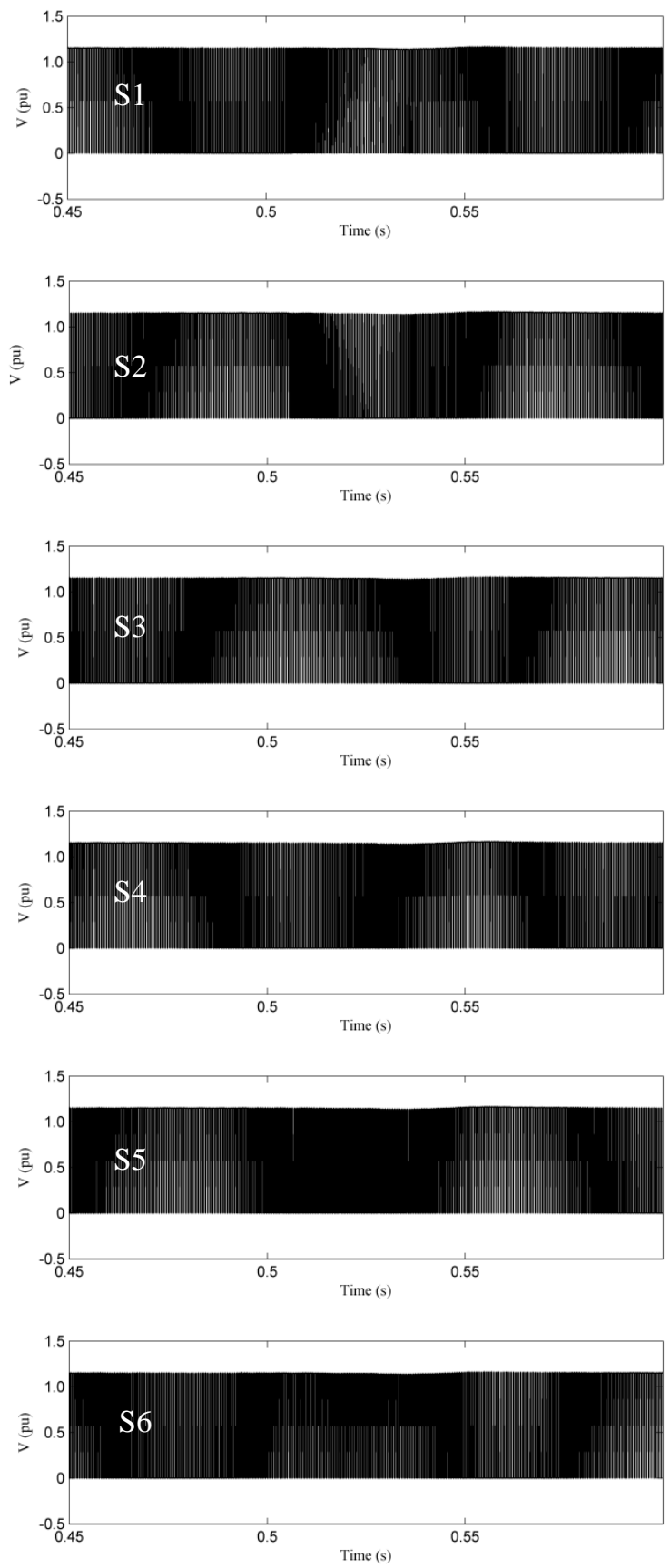

Fig. 12. Voltage across the RSC switches during misfire in S1within RSC
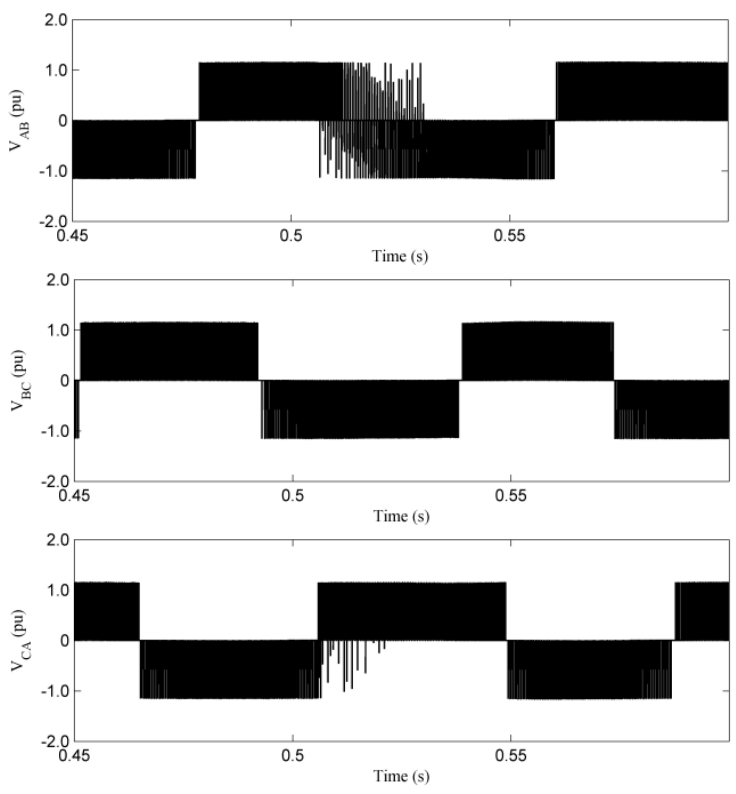

Fig. 13. Voltage across RSC terminals during misfire in S1 within RSC

\section{B. Fire-through Fault}

Fig. 14 shows the dynamic response of the studied system when fire-through takes place within the GSC. As shown in Fig. 14(a), without SMES the dispatched power will be dropped to $0.1 \mathrm{pu}$ during the fault and it takes $0.2 \mathrm{~s}$ to settle down to its nominal steady state level after fault clearance. SMES unit slightly improves the power and rectify it to 0.25 pu during the fault and it reduces the settling time. Fig. 14(b) shows that with the SMES unit connected to the system, shaft speed oscillation is reduced and settling time is substantially decreased after the clearance of the fault, thus shaft speed reaches steady condition faster than the system without SMES. Moreover, the voltage at the PCC is also improved from $0.6 \mathrm{pu}$ during fault with no SMES unit connected to the system to 0.8 pu when SMES is connected as shown in Fig. 14(c).
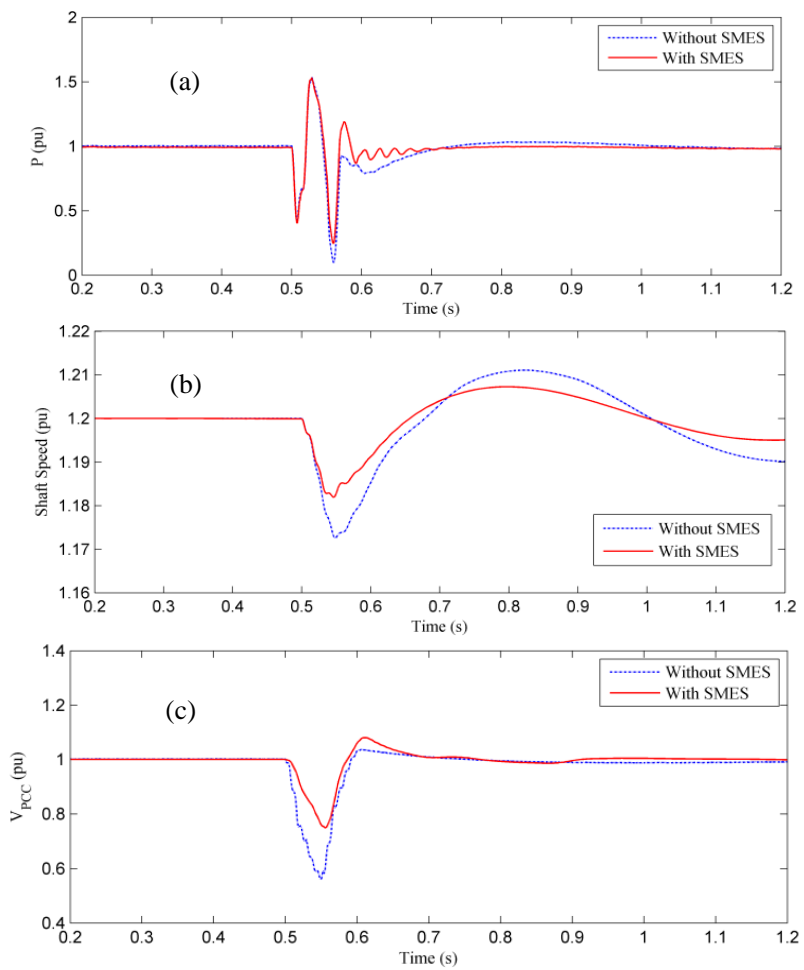

Fig. 14. Effect of GSC fire-through on DFIG dynamic performance without and with SMES unit; (a) power, (b) shaft speed, (c) voltage at PCC. 

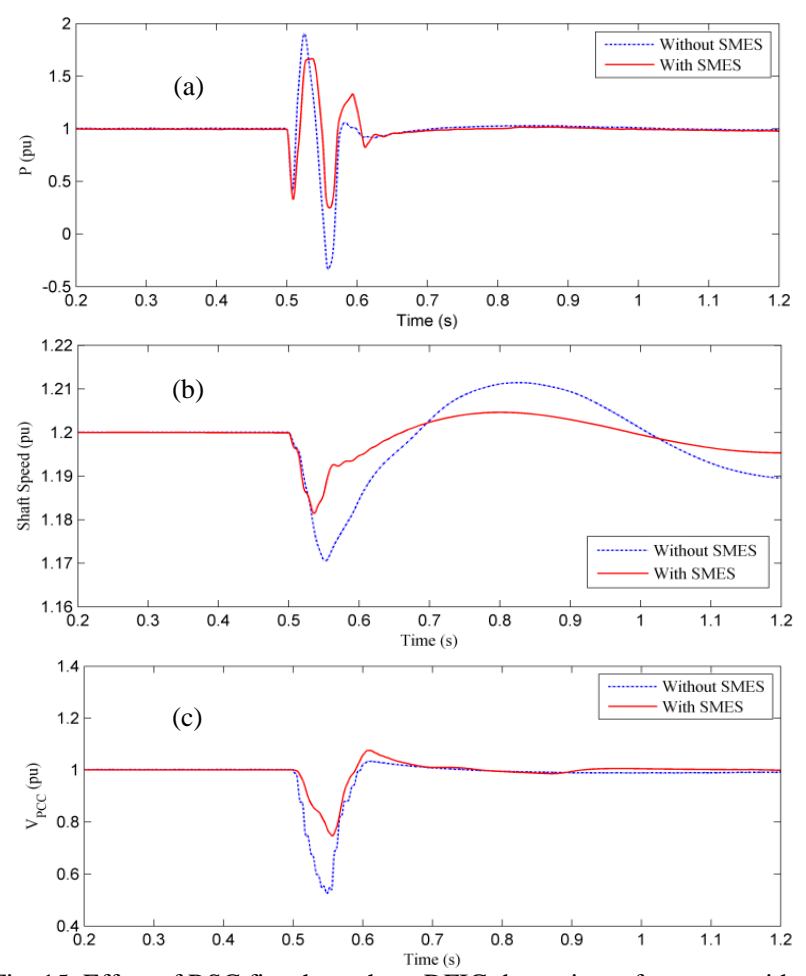

Fig. 15. Effect of RSC fire-through on DFIG dynamic performance withou and with SMES unit; (a) power, (b) shaft speed, (c) voltage at PCC.

Fig. 15 shows the system response when fire-through takes place within the RSC. Without SMES unit connected to the system and during the fault, the generated power oscillates and drops to a negative level where the machine absorbs power from the grid and acts as a motor (Fig. 15(a)). In this condition, protection devices such as crowbar circuit must be activated to isolate the WECS and to protect the converter switches against excessive current. However, with the SMES unit connected to the system, the drop in generated power is modulated to $0.25 \mathrm{pu}$ as shown in Fig. 15(a). Also, both shaft speed and $V_{P C C}$ are significantly improved by the connection of the SMES unit to the system as shown in Figs. 15(b) and (c), respectively. As can be noticed in Fig 15(c), fire-through causes the voltage at the PCC to drop to 0.6 pu without SMES compensation. This level is regulated to $0.8 \mathrm{pu}$ with the SMES connection. With PCC voltage sag of $0.2 \mathrm{pu}$ that lasts for $0.05 \mathrm{~s}$, the DFIG operation can be maintained according to some grid codes such as Spain grid code that specifies $0.5 \mathrm{pu}$ maximum voltage sag to maintain the wind turbine connected to grid during fault conditions [41]. It is worth mentioning that the capability of voltage regulation for SMES is a function of voltage source converter sizing and by increasing the SMES capability; the voltage regulation can be further improved, but at the price of higher SMES cost.

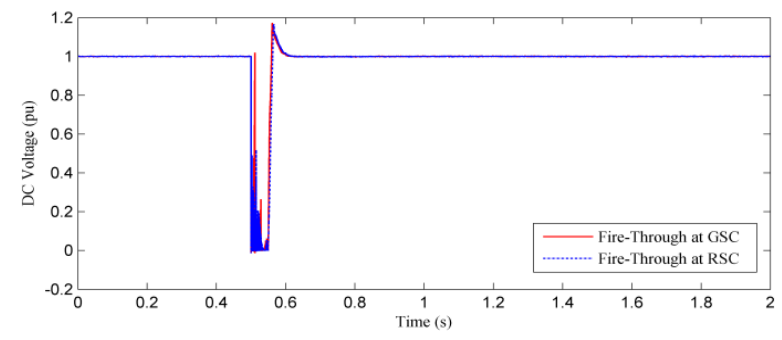

Fig. 16. Effect of GSC and RSC fire-through on the DFIG DC-link voltage.
The voltage across the dc-link capacitor when fire-through fault takes place within GSC or RSC is shown in Fig. 16 which reveals that in both cases, the voltage across the capacitor drops to zero level during the fault and the voltage is recovered to its nominal level upon fault clearance.
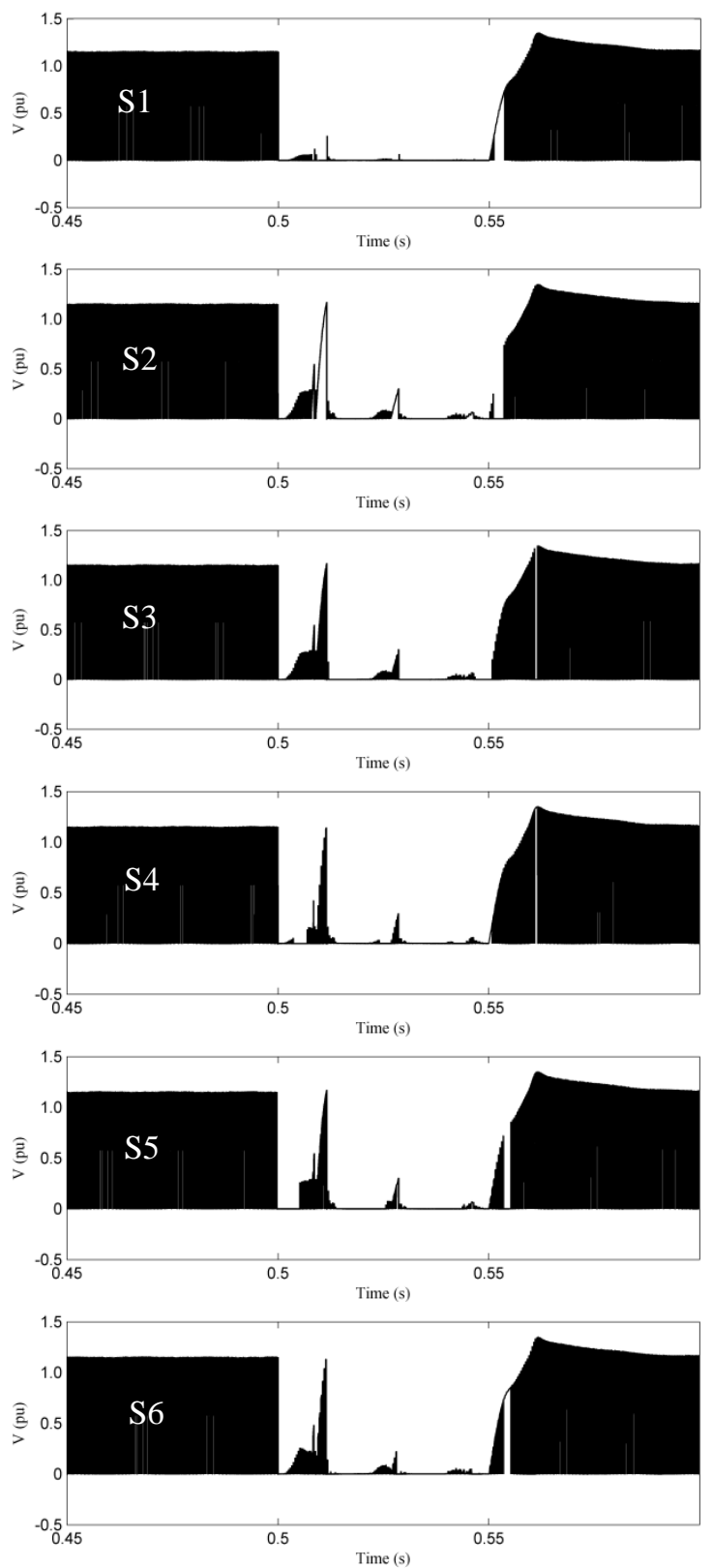

Fig. 17. Voltages across GSC switches during fire-through in S1 within GSC

When fire-through occurs on switch S1 of the GSC or RSC, a line to line short circuit will be established across the converter terminals when the other upper switches (S3 and S5) take over conduction causing line to line voltage drops to zero level during the fault.

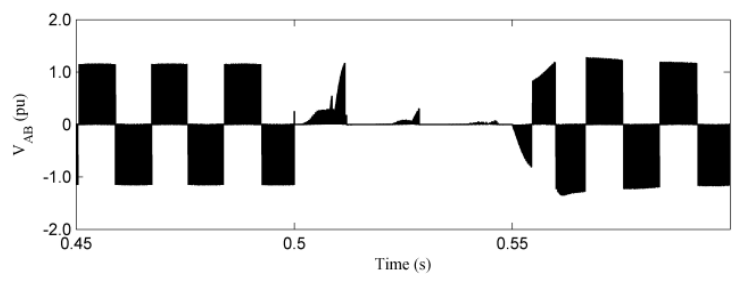



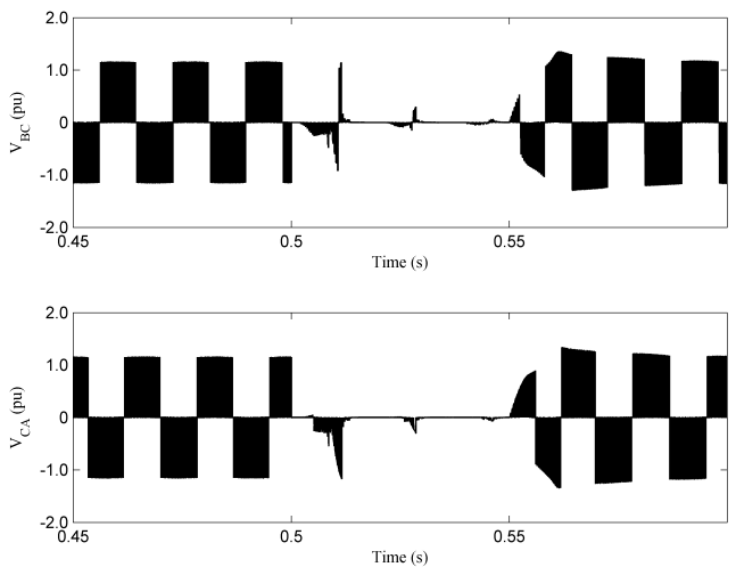

Fig. 18. Voltage across GSC terminals during fire-through in S1 within GSC.
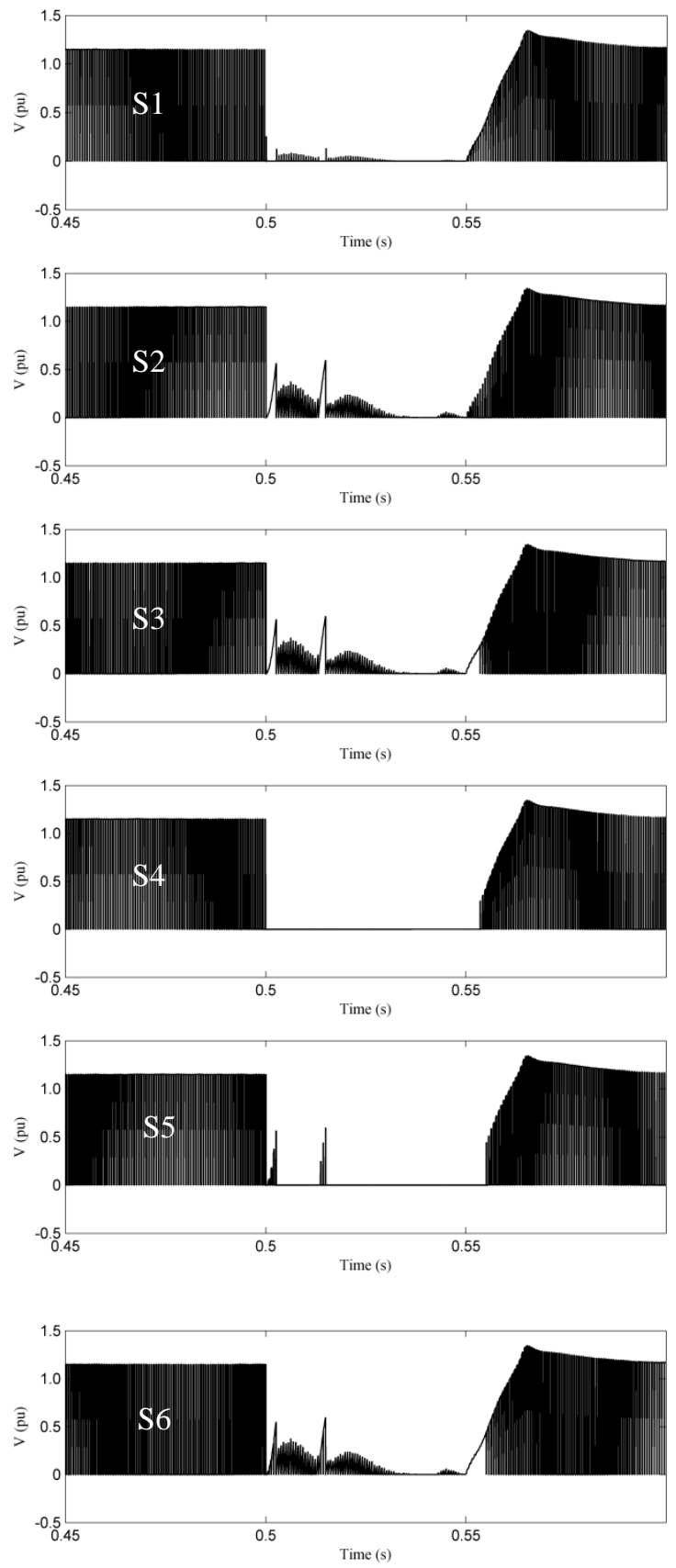

Fig. 19. Voltage across RSC switches during fire-through in S1 within RSC.
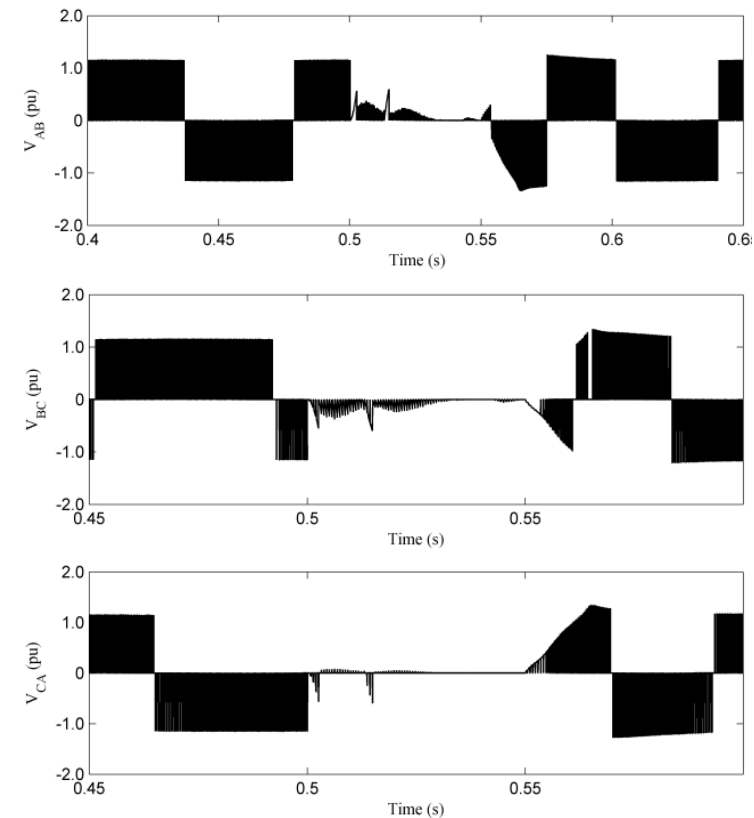

Fig. 20. Voltage across RSC terminals during fire-through in S1 within RSC.

Moreover, when switch S2 takes over conduction, a short circuit will be established across the dc-link capacitor and the voltage across the capacitor reduces to zero level as previously shown in Fig. 16 which in turn affects the voltage across all switches. The impact of fire-through fault on voltages across converter switches and converter terminal voltages are quite similar when the fault takes place in the GSC or RSC as can be seen in Figs. 17 to 20. This analysis shows that the impact of fire-through fault will be alike when it takes place in any other switch within the same converter.

\section{SMES Behaviors}

The SMES coil behavior during misfire and fire-through events are shown in Figs. 21 and 22, respectively. Fig. 21(a) shows the per-unit power of the SMES unit with a base value of 1 MVA. SMES power is discharged to the system during the event of misfire within the RSC. On the other hand, due to the insignificant impact of the misfire within the GSC on system performance, the SMES controller has a slight response during fault. The energy exchange between the SMES coil and the system during misfire within GSC and RSC can be examined through duty cycle response and the voltage across the SMES coil shown in Figs. 21(b) and 21(c), respectively where the duty cycle is maintained at 0.5 level (standby condition) and the voltage across the coil is maintained at zero level by short circuiting the SMES coil using the bypass switches shown in Fig. 1 during normal operating conditions. The duty cycle drops to a level below 0.5 (discharge condition) when misfire occurs within the RSC. The bypass switches are opened to allow for energy transfer and the voltage across the coil becomes negative.

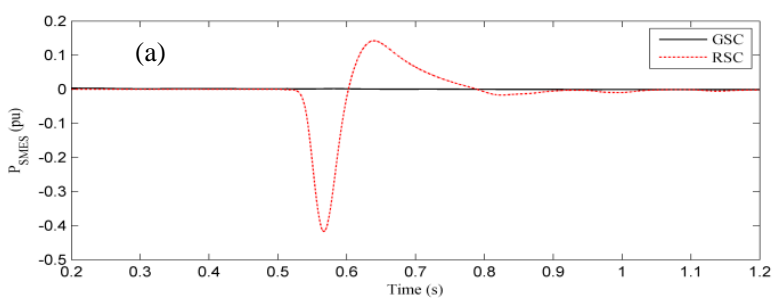



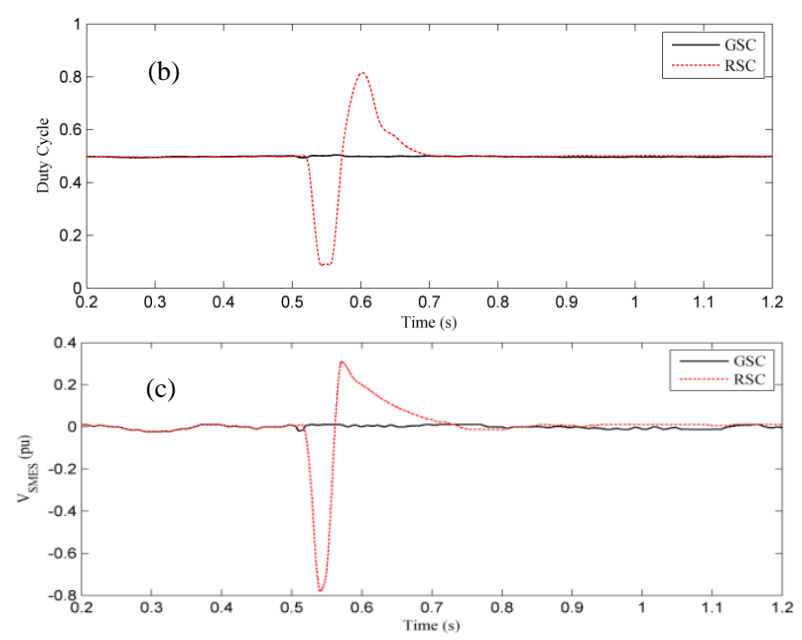

Fig. 21. SMES behaviors during misfire fault; (a) SMES output power, (b) duty cycle, (c) voltage across SMES coil.

When the misfire within RSC is cleared, SMES coil energy recovery takes place by controlling the duty cycle to be in a level higher than 0.5 (charging condition) until maximum energy stored is retained after which the duty cycle drops back to 0.5 level to maintain the voltage across the coil at zero level during normal operating conditions.

The SMES coil behavior when fire-through occurs within GSC and RSC is similar to its behavior for misfire within RSC shown in Fig. 21. However, more power discharge is demanded from the SMES in case of RSC fire-through as shown in Fig. 22(a). Also, oscillations in the duty cycle response and the voltage across the SMES coil are noticeable during and after the fault clearance as shown in Figs. 22(b) and 22(c). Fig. 22 shows that the SMES coil discharges more power to the system during fire-through within RSC than the case when fire-through takes place within GSC. This is attributed to the severity of RSC firethrough when compared to the same fault within GSC as elaborated in section B above. The SMES parameters used for this study are provided in the Appendix (Table V).
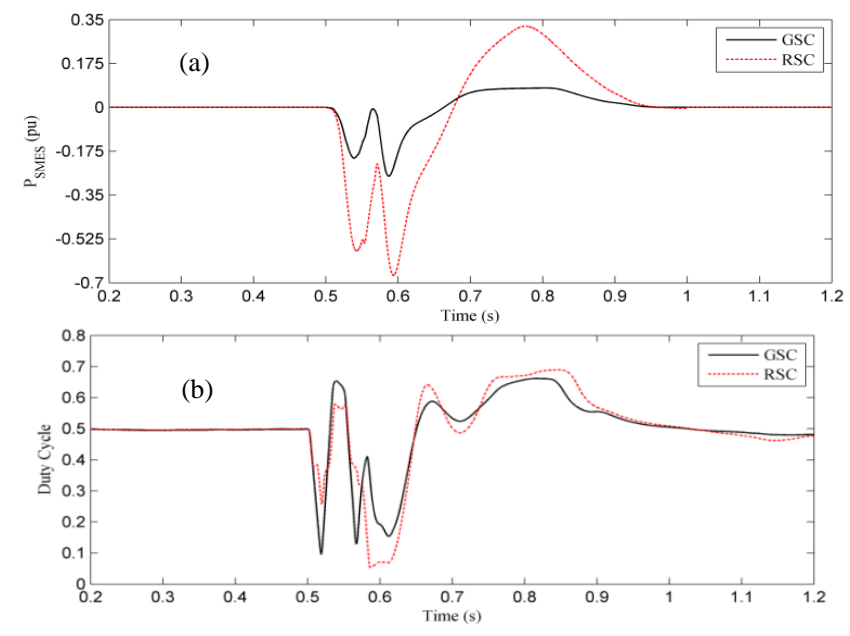

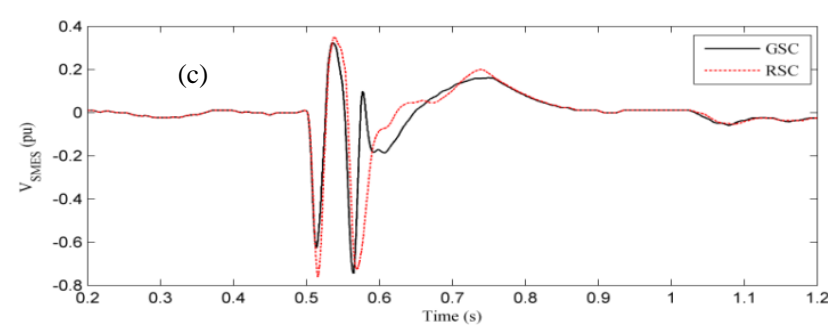

Fig. 22. SMES behaviors during fire-through fault; (a) SMES output power, (b) duty cycle, (c) voltage across SMES coil.

\section{SMES Unit Cost}

The cost of a SMES unit in a large interconnected system should take into account the purpose it is used for, the location it will be installed and the technical benefits it will introduce to the system. The capital cost of SMES unit lies in using a cryogenic system equipped with liquid Helium to maintain the conductor within low temperature. However, with the recent development of high-temperature superconductors (HTS) [42], [43] equipped with less expensive liquid Nitrogen as a cryogenic medium, the cost of SMES is becoming commercially affordable $[6,30]$.

According to [44], the cost of 3 MW DFIG-based WECS is around $\$ 350 \mathrm{~K}-517 \mathrm{~K}$ depending on the gear box configuration. On the other hand, the cost of SMES unit is around $\$ 85 \mathrm{~K}-125 \mathrm{~K} / \mathrm{MJ}$ depending on the selected configuration [45]. According to these estimations, the cost of the proposed SMES unit is about $25 \%$ of the 3 MW DFIG-based WECS investigated in this study. With the advance in superconducting material technology, the price of SMES unit is becoming even lower. A recent study [46] estimates the cost of a SMES unit to be $\$ 20 \mathrm{~K} / \mathrm{MW}$ that makes the cost of the 1 MW SMES unit proposed in this study equivalent to $7 \%$ of the 3 MW DFIG-based WECS.

It is worth mentioning that, the real application of SMES unit in WECS is to improve the dynamic performance of a large wind farm consisting of several wind turbines. The single wind turbine example used in this study is meant to simplify the investigation, introduce a new application for SMES unit in WECS and to prove its effectiveness in improving system performance during DFIG converters faults. Although SMES application in WECS is not commercialized yet, its superior technical advantages could qualify it as a competitive storage and management device in the near future especially with the global trend to develop smart grids [47-49].

\section{CONCLUSION}

This paper investigates the detrimental impacts of misfire and fire-through faults within the GSC and RSC of DFIGbased WECS on the dynamic performance of the system. A proposed SMES controller based on HCC and fuzzy logic to overcome these detrimental impacts is introduced. The main conclusions can be summarized as below:

- The proposed hysteresis current, fuzzy logic-based controller which is relatively simple and easy to implement can improve the power dispatch of DFIG in the event of converter internal faults.

-While simulation study shows that misfire has less detrimental impact on the DFIG dynamic performance, fire-through has a severe influence on the WECS dynamic 
behavior, and will lead to the disconnection of the wind turbine and converters to avoid any damages especially when fire-through takes place within the RSC.

- The SMES unit is still a costly piece of equipment, however due to the development of high temperature superconducting materials, its applications in power systems is expected to become more viable in the near future due to its superior advantages over other FACTS devices.

\section{APPENDIX}

TABLE II

PARAMETERS OF DFIG AND PCC BUS

\begin{tabular}{|c|c|}
\hline Rated Power & $3 \mathrm{MW}$ \\
\hline Stator Voltage & $575 \mathrm{~V}$ \\
\hline Frequency & $60 \mathrm{~Hz}$ \\
\hline $\mathrm{R}_{\mathrm{S}}$ & $0.023 \mathrm{pu}$ \\
\hline $\mathrm{R}_{\mathrm{R}}$ & $0.016 \mathrm{pu}$ \\
\hline $\mathrm{V}_{\text {CONVERTER Base Value }}$. & $1000 \mathrm{~V}$ \\
\hline $\mathrm{V}_{\text {PCC }}$ Base Value & $25 \mathrm{KV}$ \\
\hline \multicolumn{2}{|c|}{ TABLE III } \\
PARAMETERS OF TRANSMISSION LINE \\
\begin{tabular}{|c|c|}
\hline $\mathrm{R}_{1}, \mathrm{R}_{0}(\Omega / \mathrm{km})$ & $0.1153,0.413$ \\
\hline $\mathrm{L}_{1}, \mathrm{~L}_{0}(\mathrm{H} / \mathrm{km})$ & $1.05 \times 10^{-3}, 3.32 \times 10^{-3}$ \\
\hline $\mathrm{C}_{1}, \mathrm{C}_{0}(\mathrm{~F} / \mathrm{km})$ & $11.33 \times 10^{-9}, 5.01 \times 10^{-9}$ \\
\hline
\end{tabular}
\end{tabular}

TABLE IV

DATA OF GRID

\begin{tabular}{|c|c|}
\hline Grid Capacity & $2500 \mathrm{MVA}$ \\
\hline Grid Voltage & $120 \mathrm{KV}$ \\
\hline $\mathrm{X} 0 / \mathrm{X} 1$ & 3 \\
\hline
\end{tabular}

TABLE V

PARAMETERS OF SMES UNIT

\begin{tabular}{|c|c|}
\hline Rated Energy & $1.0 \mathrm{MJ}$ \\
\hline $\mathrm{L}_{\mathrm{SM}}$ & $0.5 \mathrm{H}$ \\
\hline Rated I & $2000 \mathrm{~A}$ \\
\hline Rated Power & $1.0 \mathrm{MW}$ \\
\hline $\mathrm{C}_{\mathrm{dC}-\text { link }}$ & $18 \mathrm{mF}$ \\
\hline $\mathrm{V}_{\mathrm{SMES}}$ Base Value & $10 \mathrm{KV}$ \\
\hline
\end{tabular}

\section{ACKNOWLEDGMENT}

The first author would like to thank The High Education Ministry of Indonesia (DIKTI) in collaboration with State Polytechnic of Ujung Pandang and Curtin University in supporting the research.

\section{REFERENCES}

[1] F. A. Farret and M. G. Simoes, Integration of alternative sources of energy, New Jersey: A John Wiley \& Son. Inc. 2006

[2] T. Ackerman, Wind Power in Power System, West Sussex: John Wiley and Sons Ltd. 2005

[3] F. Blaabjerg and Z. Chen, Power Electronics for Modern Wind Turbines, Aalborg: Morgan \& Claypool Publishers, pp. 18.2006

[4] P. W. Carlin, A. S. Laxson, and E. B. Muljadi, "The History and State of the Art of Variable-Speed Wind Turbine Technology," NREL, National Renewable Energy Laboratory. 2001

[5] H. Polinder, D.-J. Bang, H. Li, and Z. Chen, "Concept Report on Generator Topologies, Mechanical \& Electromagnetic Optimization," Delft University of Technology and Aalborg University, Delft and Aalborg. 2007

[6] A. Abu-Siada and S. Islam, "Application of SMES Unit in Improving the Performance of an AC/DC Power System", IEEE Transactions on Sustainable Energy, vol. 2, pp. 109-121. 2011
[7] J. Arrillaga, High Voltage Direct Current Transmission, London: Peter Peregrinus Ltd. 1983

[8] F. W. Fuchs, "Some Diagnosis Methods for Voltage Source Inverters in Variable Speed Drives with Induction Machines A Survey" in Industrial Electronics Society Conference (IECON'03). pp. 13781385, Vol. 2. 2003

[9] H. B. Attia Sethom and M. A. Ajabi Ghedamsi,"Intermittent Misfiring Default Detection and Localisation on a PWM Inverter Using Wavelet Decomposition", Journal of Electrical System, Vol. 4, pp. 1-12. 2008

[10] K. R. Padiyar, HVDC Power Transmission Systems, New Delhi: John Wiley \& Sons. 1990

[11] L. Bin and S. Sharma, "A survey of IGBT fault diagnostic methods for three-phase power inverters," in International Conference on Condition Monitoring and Diagnosis, 2008. CMD 2008., pp. 756763. 2008

[12] Ribeiro, P. F., "SMES for enhanced flexibility and performance of FACTS devices," in International Conference on Power Engineering Society Summer Meeting, pp 1120-1130. 1999

[13] V. Akhmatov, "Analysis of Dynamic Behavior of Electric Power Systems with Large Amount of Wind Power ( $\mathrm{PhD}$ Thesis)", Electrical Power Engineering Denmark: Technical University of Denmark. 2003

[14] http://www.iea.lth.se/publications/Theses/LTH-IEA-1063.pdf, accessed. 23 October 2012.

[15] L. Shuhui and T. A. Haskew, "Analysis of Decoupled d-q Vector Control in DFIG Back-to-Back PWM Converter," in Power Engineering Society General Meeting, 2007. IEEE, 2007, pp. 1-7

[16] R. Pena, J. C. Clare, and G. M. Asher, "Doubly fed induction generator using back-to-back PWM converters and its application to variable speed wind-energy generation," Electric Power Applications, IEE Proceedings -, vol. 143, pp. 231-241, 1996.

[17] F. Zhou, G. Joos, C. Abbey, L. Jiao, and B. T. Ooi, "Use of large capacity SMES to improve the power quality and stability of wind farms," in Power Engineering Society General Meeting, 2004. IEEE, pp. 2025-2030 Vol.2. 2004

[18] M. R. I. Sheikh, S. M. Muyeen, R. Takahashi, T. Murata, and J. Tamura, "Minimization of fluctuations of output power and terminal voltage of wind generator by using STATCOM/SMES," in PowerTech, 2009 IEEE Bucharest, pp. 1-6. 2009

[19] T. Asao, R. Takahashi, T. Murata, J. Tamura, M. Kubo, A Kuwayama, and T. Matsumoto, "Smoothing control of wind power generator output by superconducting magnetic energy storage system," in Int. Conf. Electrical Machines and Systems 2007. ICEMS., pp. 302-307. 2007

[20] J. Hee-yeol, P. Dae-Jin, S. Hyo-Ryong, P. Minwon, and Y. In-Keun, "Power quality enhancement of grid-connected wind power generation system by SMES," in Power Systems Conference and Exposition, 2009. PSCE '09. IEEE/PES, pp. 1-6. 2009.

[21] M. H. Ali, P. Minwon, Y. In-Keun, T. Murata, and J. Tamura, "Improvement of Wind-Generator Stability by Fuzzy-LogicControlled SMES", IEEE Transactions on Industry Applications, vol. 45, pp. 1045-1051. 2009

[22] J. Hee-Yeol, A. R. Kim, K. Jae-Ho, P. Minwon, Y. In-Keun, K. Seok-Ho, S. Kideok, K. Hae-Jong, S. Ki-Chul, T. Asao, and J. Tamura, "A Study on the Operating Characteristics of SMES for the Dispersed Power Generation System", IEEE Transactions on Applied Superconductivity, vol. 19, pp. 2028-2031. 2009

[23] S. S. Chen, L. Wang, W. J. Lee, and Z. Chen, "Power flow control and damping enhancement of a large wind farm using a superconducting magnetic energy storage unit", Renewable Power Generation, IET, vol. 3, pp. 23-38. 2009

[24] P. F. Ribeiro, B. K. Johnson, M. L. Crow, A. Arsoy, and Y. Liu, "Energy storage systems for advanced power applications", Proceedings of the IEEE, vol. 89, pp. 1744-1756. 2001

[25] S. C. Smith, P. K. Sen, and B. Kroposki, "Advancement of energy storage devices and applications in electrical power system," in Power and Energy Society General Meeting - Conversion and Delivery of Electrical Energy in the 21st Century, 2008 IEEE, pp. 18. 2008

[26] H. Chen, T. N. Cong, W. Yang, C. Tan, Y. Li, and Y. Ding, "Progress in electrical energy storage system: A critical review", Progress in Natural Science, vol. 19, pp. 291-312. 2009

[27] E. Ancha, V. G. Agelidis, O. Anaya-Lara, and T. J. E. Miller, Power electronic control in electrical systems, Oxford: Newnes. 2002 
[28] N. Koshizuka, F. Ishikawa, H. Nasu, M. Murakami, K. Matsunaga, S. Saito, O. Saito, Y. Nakamura, H. Yamamoto, R. Takahata, Y. Itoh, H. Ikezawa, and M. Tomita, "Progress of superconducting bearing technologies for flywheel energy storage systems", Physica C: Superconductivity, vol. 386, pp. 444-450. 2003

[29] M. Beaudin, H. Zareipour, A. Schellenberglabe, and W. Rosehart, "Energy storage for mitigating the variability of renewable electricity sources: An updated review", Energy for Sustainable Development, vol. 14, pp. 302-314. 2010

[30] A. Abu-Siada, "Application of Superconducting Magnetic Energy Storage Units to Improve Power System Performance (PhD Thesis)," in Electrical and Computer Engineering Perth: Curtin University of Technology. 2004

[31] M. H. Ali, W. Bin, and R. A. Dougal, "An Overview of SMES Applications in Power and Energy Systems", IEEE Trans. Sustainable Energy, vol. 1, pp. 38-47. Apr. 2010

[32] A. M. Shiddiq-Yunus, M. A. S. Masoum, and A. Abu-Siada, "Application of SMES to Enhance the Dynamic Performance of DFIG During Voltage Sag and Swell", IEEE Transactions on Applied Superconductivity. vol. 22, Issue: 4, p. 5702009, Aug. 2012.

[33] K. Bong-Hwan, K. Tae-Woo, and Y. Jang-Hyoun, "A novel SVMbased hysteresis current controller", IEEE Transactions on Power Electronics, vol. 13, pp. 297-307. 1998

[34] M. Milosevic. "Hysteresis Current Control in Three-Phase Voltage Source Inverter," http://www.eeh.ee.ethz.ch/uploads/tx_ethpublications/milosevic hysteresis.pdf, accessed. 19 February 2011

[35] L. Malesani and P. Tenti, "A novel hysteresis control method for current-controlled voltage-source PWM inverters with constant modulation frequency", IEEE Transactions on Industry Applications, vol. 26, pp. 88-92. 1990

[36] I. D. Hassan, R. M. Bucci, and K. T. Swe, "400 MW SMES power conditioning system development and simulation", IEEE Transactions on Power Electronics vol. 8, pp. 237-249. 1993

[37] H. Li and M. M. Gupta, "Fuzzy Logic and Intelligent System," Massachusetts: Kluwer Academic Publisher. 1995

[38] J. Rogers, H. Boenig, R. Schermer, and J. Hauer, "Operation of the $30 \mathrm{MJ}$ superconducting magnetic energy storage system in the Bonneville Power Administration electrical grid", IEEE Trans. Magn., vol. 21, pp. 752-755. Mar. 1985

[39] J. Shi, Y. Tang, T. Dai, L. Ren, J. Li, S. Cheng, "Determination of SMES capacity to enhance the dynamic stability of power system", Physica C: Superconductivity and Its Application, 2010. pp 17071710

[40] M. G. Rabbani, J. B. X. Devotta, and S. Elangovan, "Application of simultaneous active and reactive power modulation of SMES unit under unequal \& alpha;-mode for power system stabilization", IEEE Trans. Power Syst., vol. 14, pp. 547-552. May 1999.

[41] M. Altin, O. Goksu, R. Teodorescu, P. Rodriguez, B. B. Jensen, and L. Helle, "Overview of recent grid codes for wind power integration," in 12th International Conference on Optimization of Electrical and Electronic Equipment (OPTIM), 2010, pp. 1152-1160

[42] D. Sekiguchi, T. Nakamura, S. Misawa, H. Kitano, T. Matsuo, N. Amemiya, Y. Ito, M. Yoshikawa, T. Terazawa, K. Osamura, Y Ohashi, N. Okumura, "Trial test of fully HTS induction/synchronous machine for next generation electric vehicle", IEEE Transaction on Applied Supercond., vol. 22, pp. 5200904, 2012.

[43] X. Zhou, J. X. Jin, W. Xu, X. Y. Chen, Y. Chen, J.Y. Zhang, W. Z. Gong, A. L. Ren, Y. Xin., "Dynamic switching control of power charge and discharge in an HTS coil for SMES application", in Innovative Smart Grid Technologies - Asia (ISGT Asia), 2012 IEEE, pp. 1 - 3. 2012

[44] Li, H., Chen, Z., and Polinder, H.: 'Research report on numerical evaluation of various variable speed wind generator systems', Institute of Energy Technology, 2006

[45] V. Karasik, K. Dixon, C. Weber, B. Batchelder, G. Campbell, and P. F.Ribeiro, "SMES for power utility applications: A review of technical and cost considerations," IEEE Trans. Appl. Supercond., vol. 9, no. 2,pp. 541-546, Jun. 1999.

[46] S. Nomura, T. Shintomi, S. Akita, T. Nitta, R. Shimada, S. Meguro, "Technical and cost evaluation on SMES for electric power compensation", IEEE Transaction on Applied Supercond. 2010. pp. 1373-1378.

[47] Y.-S. Lee, "Decentralized suboptimal control of power systems with superconducting magnetic energy storage units," Int. J. Power EnergySyst., vol. 21, no. 2, pp. 87-96, 2001

[48] P. D. Baumann, "Energy conservation and environmental benefits that may be realized from superconducting magnetic energy storage," IEEETrans. Energy Convers., vol. 7, no. 2, pp. 253-259, Jun. 1992.
[49] A. Abu-Siada and S. Islam "Superconducting Magnetic Energy Storage units, an Efficient Energy Technology for Power Systems", proceeding of the International Middle East Power System Conference MEPCON'08, Egypt, Feb. 2008.

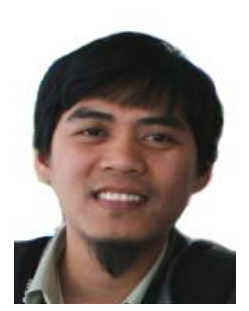

A. M. Shiddiq Yunus (S'2011) received his B.Sc from Hasanuddin University, Indonesia in 2000 and his M.Eng.Sc from Queensland University of Technology (QUT), Australia in 2006 both in Electrical Engineering and the $\mathrm{PhD}$ degree from Curtin University, Australia in 2012. He is currently lecturer with the Department of Mechanical Engineering, Energy Conversion Study Program, State Polytechnic of Ujung Pandang, Indonesia. His special fields of interest include superconducting magnetic energy storage (SMES), renewable energy and smart grid. He is a regular reviewer for IET Power Electronics Journal and IEEE Transaction on Applied Superconductivity.

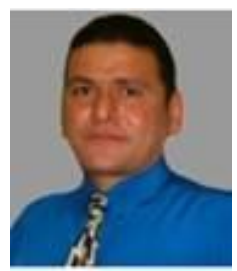

A. Abu-Siada (M'07, SM'12) received his B.Sc and M.Sc. degrees from Ain Shams University, Egypt and the $\mathrm{PhD}$ degree from Curtin University, Australia, All in Electrical Engineering. Currently, he is a senior lecturer in the Department of Electrical and Computer Engineering at Curtin University. His research interests include power system stability, condition monitoring, power electronics and power quality. He is editor-in-chief for the electrical and electronic engineering international journal, a regular reviewer for many IEEE Transactions and a vice chair of the IEEE CIS, WA Chapter. He is a senior member of the IEEE.

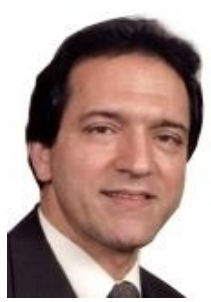

Mohammad A. S. Masoum (S'88-M'91-SM'05) received his B.S., M.S. and Ph.D. degrees in Electrical and Computer Engineering in 1983, 1985, and 1991, respectively, from the University of Colorado, USA. Dr. Masoum's research interests include optimization, power quality and stability of power systems/electric machines and distributed generation. Currently, he is a Professor and the Discipline Leader and Course Coordinator for Power System Engineering at the Electrical and Computer Engineering Department, Curtin University, Australia. He is the co-author of Power Quality in Power Systems and Electrical Machines (Elsevier, 2008) and Power Conversion of Renewable Energy Systems (Springer, 2011). Dr Masoum is the editor-in-chief for American Journal of Engineering \& Applied Science, an editor of Australian Journal of Electrical \& Electronic Engineering, and a senior member of IEEE. 